DE

M E D I C I N A

T R O P I C A L

$\mathrm{DE}$

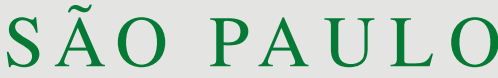

JOURNAL OF THE SÃO PAULO INSTITUTE OF TROPICAL MEDICINE

'Universidade de São Paulo, Faculdade de Medicina, Hospital das Clínicas, São Paulo, São Paulo, Brazil

'Universidade de São Paulo, Instituto de Medicina Tropical de São Paulo, São Paulo, São Paulo, Brazil

3Universidade de São Paulo, Faculdade de Medicina, Hospital das Clínicas, Grupo De Controle de Infecções Hospitalares, São Paulo, São Paulo, Brazil

${ }^{4}$ Universidade de São Paulo, Faculdade de Medicina Veterinária e Zootecnia, São Paulo, São Paulo, Brazil

${ }^{5}$ Universidade de São Paulo, Faculdade de Medicina, Hospital Universitário, São Paulo, São Paulo, Brazil

${ }^{6}$ Universidade de São Paulo, Faculdade de Medicina, Hospital das Clínicas, Instituto de Medicina Física e de Reabilitação, São Paulo, São Paulo, Brazil

Correspondence to: Taniela Marli Bes Universidade de São Paulo, Instituto de Medicina Tropical de São Paulo, Rua Dr Enéas Carvalho de Aguiar, 470, CEP 05403-000, São Paulo, SP, Brazil

E-mail: tanielabes@gmail.com

Received: 2 July 2018

Accepted: 13 September 2018

\section{Prevalence of methicillin-resistant Staphylococcus aureus colonization in individuals from the community in the city of Sao Paulo, Brazil}

\author{
Taniela Marli Bes ${ }^{1,2}$, Roberta Ruedas Martins², Lauro Perdigão1,3, Diego \\ Mongelos ${ }^{2}$, Luisa Moreno ${ }^{4}$, Andrea Moreno ${ }^{4}$, Gerson Salvador de Oliveira ${ }^{5,6}$, \\ Silvia Figueiredo Costa ${ }^{1,2}$, Anna Sara Levin ${ }^{1,2,3}$
}

\section{ABSTRACT}

Staphylococcus aureus (SA) is a commensal habitant of nasal cavities and skin. Colonization by community-acquired methicillin-resistant SA (CA-MRSA) is associated with infections in patients who have not been recently hospitalized. The aim of this study is to determine the prevalence of MRSA colonization in an outpatient population, currently unknown in Brazil. Three-hundred patients or caregivers from two teaching hospitals were included. A questionnaire was applied and nasal swabs were obtained from patients. Swabs were inoculated in brain heart infusion (BHI) with $2.5 \% \mathrm{NaCl}$ and seeded in mannitol. Suspicious colonies were subjected to MALDI-TOF MS Microflex ${ }^{\mathrm{TM}}$ identification. Antimicrobial susceptibility test for oxacillin was performed for SA-positive samples by microdilution. Polymerase chain-reactions for detection of mecA and $c o \mathrm{~A}$ genes were performed for resistant samples. Data about MRSA carriers were compared with non-carriers. There were 127 S. aureus isolates, confirmed by MALDI-TOF. Only seven (2.3\%) were MRSA and positive for mecA and $c o A$ genes. Factors associated with MRSA carriage were African ethnicity, skin diseases or antibiotic use. The majority of them were from Dermatology clinics. Prevalence of MRSA colonization in individuals from the community was low in our study $(2.3 \%)$. This finding raises the hypothesis of inter-household transmission of SA, although we did not find any association between MRSA-colonization and the shared use of personal objects. Given the low prevalence of MRSA carriers observed, empirical antimicrobial coverage for MRSA in community-acquired infections should be not necessary.

KEYWORDS: Staphylococcus aureus. MRSA. Skin colonization.

\section{INTRODUCTION}

Staphylococcus aureus (SA) is a human commensal and inhabits nasal cavities and skin. It is estimated that $30-60 \%$ of the population are transiently colonized and $20 \%$ carry SA persistently ${ }^{1,2}$.

Although originally a nosocomial pathogen, methicillin-resistant SA (MRSA) has caused community-acquired infections since the $2000 \mathrm{~s}^{3}$. The first communityacquired MRSA (CA-MRSA) report was in Australia in 1993, in local indigenous people, and since then outbreaks have been described in different contexts. In Brazil CA-MRSA was reported sporadically ${ }^{4-7}$.

CA-MRSA is associated with infections in patients with no recent history of hospital admission and does not appear to be related to the classic risk factors for MRSA colonization ${ }^{8}$. Risk factors for CA-MRSA are not well established, and 
include: living in agglomerations, children, antibiotic use for less than one year, chronic skin disease, HIV infection, and low socioeconomic level ${ }^{1,9,10}$.

Currently the prevalence of MRSA colonization in the community is unknown in Brazil.

The objective of this study was to determine the prevalence of MRSA-colonized individuals in a population from an outpatient healthcare facility.

\section{MATERIALS AND METHODS}

Outpatients and persons who accompany them at two hospitals were included in the study during the period from January to April 2017. Hospital das Clinicas (HC) is a tertiary-care facility and Hospital Universitario (HU) is a community hospital. Both are teaching facilities affiliated with the University of Sao Paulo, Brazil. The research was conducted after the approval of the Research Ethics Committees of both hospitals $\left(\mathrm{N}^{\circ} 1.887 .780\right.$ and 1.930.074). Data were consolidated and analyzed, and patients' identities were confidential.

Inclusion criteria: Individuals with at least 18 years of age who passed the entrance doors of the outpatient Infectious Diseases and Dermatology Clinics at HC, emergency room, at both hospitals and the immunization center.

Exclusion criteria: history of use of long-term catheters, undergoing surgery or hospitalization within the last year.

Individuals included in the study, after signing the consent form, answered a questionnaire on personal data; demographics; daily habits; sports; personal hygiene; the presence of pets at home; illicit drug use; family members living in the same household; public transport (bus, subway or train); trips in the last year; frequency at motels, gyms, swimming pools or other crowded places; history of diseases such as Aids, cutaneous conditions, sexually transmitted diseases and use of antibiotics in the last year.

The number of subjects to be included in the study was calculated taking into account a population of 10 million inhabitants, a prevalence of MRSA colonization of $2 \%$ in this population, a $95 \%$ confidence interval with a $5 \%$ variation. The sample was composed of 300 subjects, divided equally between the five sectors, with 60 each.

For sample collection, swabs (COPAN Venturi Transystem ${ }^{\circledR}$, COPAN Diagnostics Inc., Murrieta, California, USA) were used. Samples were collected from the anterior nares by gently rotating the swab in each nare. One sample was obtained from each subject. Swabs were initially inoculated in Brain Heart Infusion medium (BHI) with $2.5 \% \mathrm{NaCl}$ to stimulate the growth of cutaneous agents, incubated for $24 \mathrm{~h}$ and then seeded on regular mannitol agar. Samples that converted mannitol agar to yellow staining were subjected to MALDI-TOF MS Microflex ${ }^{\text {TM }}$ identification (Bruker Daltonics, Billerica, Massachusetts, USA). The criteria for interpreting the results were: scores $=2.0$ were accepted for species assignment and scores $=1.7$ and $<2.0$ were used for genera identification.

SA isolates were submitted to antimicrobial susceptibility testing by microdilution for oxacillin ${ }^{11}$. Samples were tested in duplicate. Isolates identified as resistant to oxacillin were submitted to Polymerase Chain Reaction for mecA and coA genes for confirmation.

Analysis of data: individuals colonized with MRSA strains from the community and without hospitalization within the past year were compared with non-colonized individuals. For the analysis of the dichotomous variables, non-parametric chi-square test and Fisher's exact test were used. Numerical variables were analyzed using the Student $\mathrm{T}$ test. Also, means and standard deviations were presented.

Statistical analysis was performed with the Epi Info v3.1.3 (StatCalc Statistical Calculators).

\section{RESULTS}

Three hundred samples were collected from patients and accompanying persons: $61 \%$ were female and $95 \%$ were heterosexual. None were military in the last year; two had been incarcerated at some point during their lives but had been free for more than one year. None were intravenous drug users or lived in the same household as a drug user. Eight reported sharing a home with marijuana users, three with inhaled cocaine users andone with volatile product inhalers. Two were tobacco smokers.

Of the 300 samples collected, 127 were positive for $S$. aureus of which seven had a MIC $=4 \mu \mathrm{g} / \mathrm{mL}$ (4-128) and were positive for $c o \mathrm{~A}$ and $m e c \mathrm{~A}$ genes.

Five of the seven MRSA isolates were collected from patients or persons that accompanied patients at the Dermatology outpatient clinic. When comparing MRSA carriers with non-carriers, the Dermatology unit was associated with MRSA colonization (OR: 10.81; 95\% CI: 2.04 - $57.23 p$ : 0.0042). Other factors associated with MRSA carriage were: history of skin disease; skin color; use of motels. The use of antibiotics in the last year was a protective factor for colonization (Table 1).

\section{DISCUSSION}

We found a very low prevalence of MRSA colonization in individuals from the community: $2.3 \%$ of the entire population and 5.5\% among the persons colonized by $S$. aureus. 
Table 1 - Univariate analysis of characteristics associated with methicillin-resistant Staphylococcus aureus colonization among persons visiting outpatient clinics or emergency rooms or vaccination clinics

\begin{tabular}{|c|c|c|c|c|c|}
\hline Characteristics & $\begin{array}{c}\begin{array}{c}\text { Negative for MRSA } \\
n=293\end{array}\end{array}$ & $\begin{array}{c}\text { MRSA } \\
\mathrm{n}=7\end{array}$ & OR (odds ratio) & IC (95\%) & $p$ value \\
\hline Male & $113(39 \%)$ & $3(43 \%)$ & 1.247 & $0.274-5.679$ & 1 \\
\hline Heterosexual & $277(95 \%)$ & $7(100 \%)$ & 0 & 0 & 1 \\
\hline Black ethnicity & $56(19 \%)$ & $4(57 \%)$ & 5.642 & $1.226-25.93$ & 0.0316 \\
\hline Divides room with 1 or more people & $228(78 \%)$ & $5(71 \%)$ & 0.726 & $0.137-3.832$ & 0.658 \\
\hline Has pets in general & $140(48 \%)$ & $5(71 \%)$ & 2.732 & $0.521-14.308$ & 0.269 \\
\hline Dogs & $112(38 \%)$ & $4(57 \%)$ & 1 & $0.107-9.301$ & 1 \\
\hline Use of antiseptic soaps & $157(54 \%)$ & $3(43 \%)$ & 0.649 & $0.142-2.954$ & 0.709 \\
\hline Practices sports & $122(42 \%)$ & $2(28 \%)$ & 0.56 & $0.107-2.937$ & 0.703 \\
\hline \multicolumn{6}{|l|}{ Use of Shared Objects: } \\
\hline Shaver & $39(13 \%)$ & $1(14 \%)$ & 1.085 & $0.127-9.26$ & 1 \\
\hline Soap & $155(53 \%)$ & 5 (71\%) & 2.225 & $0.425-11.657$ & 0.455 \\
\hline Bath sponge & $141(48 \%)$ & $4(57 \%)$ & 1.437 & $0.316-6.535$ & 0.715 \\
\hline \multicolumn{6}{|l|}{ In the last year: } \\
\hline Family history of surgical procedure & $31(11 \%)$ & $1(14 \%)$ & 1.408 & $0.164-12.086$ & 0.549 \\
\hline Attended motels & $20(7 \%)$ & $3(43 \%)$ & 10.237 & $2.142-48.9292$ & 0.011 \\
\hline Beach trips & $113(39 \%)$ & $4(57 \%)$ & 2.123 & $0.466-9.665$ & 0.437 \\
\hline History of skin diseases & $35(12 \%)$ & $3(43 \%)$ & 5.528 & $1.187-25.738$ & 0.045 \\
\hline History of antibiotic use & $75(26 \%)$ & $5(71 \%)$ & 7.266 & $1.38-38.244$ & 0.016 \\
\hline Amoxicillin & $41(14 \%)$ & $1(14 \%)$ & 1.024 & $0.120-8.729$ & 1 \\
\hline Azithromycin & $15(5 \%)$ & $2(28 \%)$ & 7.413 & $1.327-41.407$ & 0.053 \\
\hline Sulfamethoxazole + Trimethoprin & $4(1 \%)$ & 0 & 0 & 0 & 1 \\
\hline Quinolones & $10(3 \%)$ & $1(14 \%)$ & 4.716 & $0.517-42.952$ & 0.232 \\
\hline $\mathrm{N} / \mathrm{A}$ & $17(6 \%)$ & $1(14 \%)$ & 2.705 & $0.308-23.769$ & 0.354 \\
\hline Use of public transportation & $233(80 \%)$ & $7(100 \%)$ & 0 & 0 & 0.351 \\
\hline Bus & $167(57 \%)$ & $6(86 \%)$ & 4.526 & $0.538-38.079$ & 0.245 \\
\hline \multicolumn{6}{|l|}{ Place of collection } \\
\hline Dermatology outpatients clinic & $55(19 \%)$ & $5(71 \%)$ & 10.818 & $2.044-57.23$ & 0.0042 \\
\hline Emegency room - HU & $59(20 \%)$ & $1(14 \%)$ & 0.661 & $0.078-5.597$ & 1 \\
\hline Emegency room - HC & $59(20 \%)$ & $1(14 \%)$ & 0.661 & $0.078-5.597$ & 1 \\
\hline Dermatology outpatients clinic & $60(20 \%)$ & 0 & 0 & 0 & 0.351 \\
\hline Imunization center & $60(20 \%)$ & 0 & 0 & 0 & 0.351 \\
\hline
\end{tabular}

The prevalence of MRSA causing cutaneous infections in patients seeking emergency services in the US varied widely from $15 \%$ to $74 \%$ in New York and Kansas City, respectively ${ }^{12}$. Over the years, the incidence of CAMRSA infections in the United States has increased from $2.5 \%$ to $39 \%$, with clonal heterogeneity in different regions ${ }^{13-15}$.

A published European study involving England, France, Germany, Italy, Greece, Romania and Spain included 205 cases of skin and soft tissue infections ${ }^{16}$. The mean prevalence of MRSA was $15.1 \%$, with no cases in Northern countries and 29\% in Southern countries.

In Brazil, community-acquired MRSA cases have been reported in the cities of Porto Alegre, Rio de Janeiro, Botucatu and Bahia. All cases have in common cutaneous involvement and the presence of PVL toxin ${ }^{6,17,18}$. A study evaluated nasal carriage of MRSA $^{19}$ among 250 first and second year students from University of Londrina, in the South of the country, with a prevalence of $2.5 \%$, a similar result to our study. Among 148 children in a daycare center 
in Northeastern Brazil, MRSA nasal carriage was $7.4 \%^{20}$.

A previous study from our group showed that among hospitalized patients in the Dermatology Unit MRSA carriage was $45 \%$, of which a quarter were communityacquired $^{21}$. Among chronic dermatologic patients, MRSA carriage is frequent, and there may be household transmission explaining the colonization of the people who accompanied patients to the Dermatology outpatient clinic in our study, although we did not find a relationship with statistical significance between colonization by MRSA and the shared use of personal objects.

Other findings in our study such as black ethnicity have been previously described by Tosas Auguet et al..$^{22}$, but we do not know how to explain it. History of antibiotic has been previously described by Gustave et al. ${ }^{23}$, who suggested that previous antibiotics use contributed to the increase of MRSA lineages in the community. The association between attending motels and MRSA colonization has not yet been described and is difficult to explain. It may be due to the collective environment and objects shared by multiple individuals.

Due to the low prevalence of colonization found in our sample, we suppose that empirical coverage against MRSA, with drugs such as clindamycin and sulfamethoxazoletrimethoprim (SMX-TMP) or even nasal decolonization with mupirocin, as recommended by the IDSA ${ }^{24}$ guideline can be used in patients from the community without risk factors, in our setting.

The IDSA guideline made the US recommends the use of MRSA coverage for patients with severe purulent or nonpurulent infection (patients with abscesses, signs of sepsis or impaired immune status), skin and soft tissue infection from the community. However, this recommendation is based on studies performed in settings different from ours, with high MRSA prevalence in the community.

Our study has limitations. Our sample was obtained in hospitals and may not represent the community. However, if so, the prevalence of MRSA may be even lower than the one we observed. The study was carried out in two hospitals in the city of Sao Paulo, not allowing extrapolation of data to the entire State or even to other regions of the country. Furthermore, due to the study design, we may have included temporary nasal carriers. On the other hand, our sample was very heterogeneous, which may allow us to generalize our results and suggest empirical therapy for infections in which $S$. aureus is suspected.

\section{CONCLUSION}

Given the low prevalence of MRSA nasal carriage found in our study (2.3\%), we believe that empirical coverage for MRSA is not necessary for patients with communityacquired infections caused by Staphylococcus aureus.

\section{REFERENCES}

1. Kluytmans J, van Belkum A, Verbrugh H. Nasal carriage of Staphylococcus aureus: epidemiology, underlying mechanisms, and associated risks. Clin Microbiol Rev. 1997;10:505-20.

2. Liu GY. Molecular pathogenesis of Staphylococcus aureus infection. Pediatr Res. 2009;65:71R-7R.

3. Seal JB, Moreira B, Bethel CD, Daum RS. Antimicrobial resistance in Staphylococcus aureus at the University of Chicago Hospitals: a 15-year longitudinal assessment in a large university-based hospital. Infect Control Hosp Epidemiol. 2003;24:403-8.

4. Udo EE, Pearman JW, Grubb WB. Genetic analysis of community isolates of methicillin-resistant Staphylococcus aureus in Western Australia. J Hosp Infect. 1993;25:97-108.

5. Ribeiro A, Dias C, Silva-Carvalho MC, Berquó L, Ferreira FA, Santos RN, et al. First report of infection with communityacquired methicillin-resistant Staphylococcus aureus in South America. J Clin Microbiol. 2005;43:1985-8.

6. Ribeiro A, Coronado AZ, Silva-Carvalho MC, Ferreira-Carvalho BT, Dias C, Rozenbaum R, et al. Detection and characterization of international community-acquired infections by methicillinresistant Staphylococcus aureus clone in Rio de Janeiro and Porto Alegre cities causing both community and hospital associated diseases. Diagn Microbiol Infect Dis. 2007;59:33945.

7. Camargo CH, Cunha ML, Bonesso MF, Cunha FP, Barbosa AN, Fortaleza CM. Systemic CA-MRSA infection following trauma during soccer match in inner Brazil: clinical and molecular characterization. Diagn Microbiol Infect Dis. 2013;76:372-4.

8. Tarai B, Das P, Kumar D. Recurrent challenges for clinicians: emergence of methicillin-resistant Staphylococcus aureus, vancomycin resistance, and current treatment options. J Lab Physicians. 2013;5:71-8.

9. Hansra NK, Shinkai K. Cutaneous community-acquired and hospital-acquired methicillin-resistant Staphylococcus aureus. Dermatol Ther. 2011;24:263-72.

10. Eady EA, Cove JH. Staphylococcal resistance revisited: community-acquired methicillin resistant Staphylococcus aureus - an emerging problem for the management of skin and soft tissue infections. Curr Opin Infect Dis. 2003;16:103-24.

11. Clinical Laboratory Standards Institute. M100: performance standards for antimicrobial susceptibility testing: $28^{\text {th }}$ informational supplement. Wayne: CLSI; 2018.

12. Moran GJ, Krishnadasan A, Gorwitz RJ, Fosheim GE, McDougal LK, Carey RB, et al. Methicillin-resistant S. aureus infections among patients in the emergency department. N Engl J Med. 2006;355:666-74. 
13. DeLeo FR, Otto M, Kreiswirth BN, Chambers HF. Communityassociated meticillin-resistant Staphylococcus aureus. Lancet. 2010;375:1557-68.

14. Chen CJ, Unger C, Hoffmann W, Lindsay JA, Huang YC, Götz F. Characterization and comparison of 2 distinct epidemic community-associated methicillin-resistant Staphylococcus aureus clones of ST59 lineage. PLoS One. 2013;8:e63210.

15. Chuang YY, Huang YC. Molecular epidemiology of communityassociated meticillin-resistant Staphylococcus aureus in Asia. Lancet Infect Dis. 2013;13:698-708.

16. Bouchiat C, Curtis S, Spiliopoulou I, Bes M, Cocuzza C, Codita I, et al. MRSA infections among patients in the emergency department: a European multicentre study. J Antimicrob Chemother. 2017;72:372-5.

17. Razera F, De Stefani S, Bonamigo RR, Olm GS, Dias CA, Narvaez GA. CA MRSA in furunculosis: case report of southern Brazil An Bras Dermatol. 2009;84:515-8.

18. Rozenbaum R, Sampaio MG, Batista GS, Garibaldi AM, Terra GM, Souza MJ, et al. The first report in Brazil of severe infection caused by community-acquired methicillin-resistant Staphylococcus aureus (CA-MRSA). Braz J Med Biol Res. 2009;42;756-60.

19. Prates KA, Torres AM, Garcia LB, Ogatta SF, Cardoso CL, Tognim MC. Nasal carriage of methicillin-resistant Staphylococcus aureus in university students. Braz J Infect Dis. 2010;14:316-8.
20. Carvalho SP, Almeida JB, Andrade YM, Silva LS, Oliveira AC, Nascimento FS, et al. Community-acquired methicillinresistant Staphylococcus aureus carrying SCCmec type IV and $\mathrm{V}$ isolated from healthy children attending public daycares in northeastern Brazil. Braz J Infect Dis. 2017;21:464-7.

21. Pacheco RL, Lobo RD, Oliveira MS, Farina EF, Santos CR, Costa SF, et al. Methicillin-resistant Staphylococcus aureus (MRSA) carriage in a dermatology unit. Clinics (Sao Paulo). 2011;66:2071-7.

22. Tosas Auguet O, Betley JR, Stabler RA, Patel A, Ioannou A, Marbach $\mathrm{H}$, et al. Evidence for community transmission of community-associated but not health-care-associated methicillin-resistant Staphylococcus aureus strains linked to social and material deprivation: spatial analysis of crosssectional data. PLoS Med. 2016;13:e1001944.

23. Gustave CA, Tristan A, Martins-Simões P, Stegger M, Benito Y, Andersen PS, et al. Demographic fluctuation of communityacquired antibiotic-resistant Staphylococcus aureus lineages: potential role of flimsy antibiotic exposure. ISME J. 2018;12:1879-94.

24. Stevens DL, Bisno AL, Chambers HF, Dellinger PE, Goldstein EJ, Gorbach SL, et al. Practice guidelines for the diagnosis and management of skin and soft tissue infections: 2014 update by the Infectious Diseases Society of America. Clin Infect Dis. 2014;59:e10-52. 